Abbreviated Key Title: Sch J Med Case Rep

ISSN 2347-9507 (Print) | ISSN 2347-6559 (Online)

Journal homepage: https://saspublishers.com

\title{
Urachal Carcinoma Associated with Sigmoid Fistula: A Rare Case Report
}

\author{
Chehboun A*, Tadsaoui S, Arharas S, Boutakioute B, Ouali Idrissi M, Cherif Idrissi El Ganouni N
}

Radiology department, Arrazi Hospital, Mohammed VI University Hospital, Marrakech

DOI: $10.36347 /$ sjmcr.2020.v08i11.013

| Received: 16.10 .2020 | Accepted: 30.10 .2020 | Published: 23.11 .2020

*Corresponding author: Chehboun A

\section{Abstract}

Urachal carcinoma is rare and aggressive, involving the urachus, a derivative of the allantois that extends from the bladder to the umbilicus the association with sigmoid-fistula is extremely rare. We report a case about a 45 year old woman who presented with an infected abdominal mass. An ultrasound and CT scan were performed revealing a large mass on the dome of the bladder extending from the urachus with a sigmoid fistula suggestive of an urachal adenocarcinoma that were confirmed on a surgical biopsy. An anterior pelvectomy was performed with a good outcome.

Keywords: Urachal Carcinoma Sigmoid Fistula.

Copyright $\odot 2020$ The Author(s): This is an open-access article distributed under the terms of the Creative Commons Attribution 4.0 International License (CC BY-NC 4.0) which permits unrestricted use, distribution, and reproduction in any medium for non-commercial use provided the original author and source are credited.

\section{INTRODUCTION}

The urachus normally obliterates during the first months of the fetal period forming the umbilical ligament. Persistant remnants are rare and can be affected with cysts or carcinoma that is rare, sigmoid fistula is even less common. We report a case of a 45 year old woman who presented an urachal carcinoma associated with sigmoid fistula.

\section{CASE RePORT}

We report a case of a 45 year old woman, with no medical history, who presented with a growing anterior abdominal mass that extend from the ombilic to the pelvic region, that is median with purulent secretions, fever and weight loss.

An ultrasound was performed, showing a mass that is heterogenous, with Doppler flow, extending from the bladder to the urachus, presenting a close contact with sigmoid, associated with a cutaneous fistula with purulent secretions (Figure 1).
A CT scan was performed confirming the ultrasound aspect, showing avoluminous infiltrative mass developed from the bladder that has an irregular thickening, extending to the umbilical region, containing microcalcifications, with heterogenous enhancement after contrast injection, and individualization of an abcess with cutaneous fistula. (Figure 2)

Delayed excretory phase CT sequence shows an opacification of the mass and of the sigmoid witnessing an urachal-sigmoid fistula (Figure 3).

A biopsy under cystoscopy was performed confirming an urachal adenocarcinoma. There were no detected metastatic sites on the chest, abdomen and pelvis scan.

The patient underwent an anterior pelvectomy with resection of a $10 \mathrm{~cm}$ long sigmoid portion followed by a Bricker ureteroenteric anastomosis. Pathology confirmed the diagnosis of urachal adenocarcinoma with negative margins.

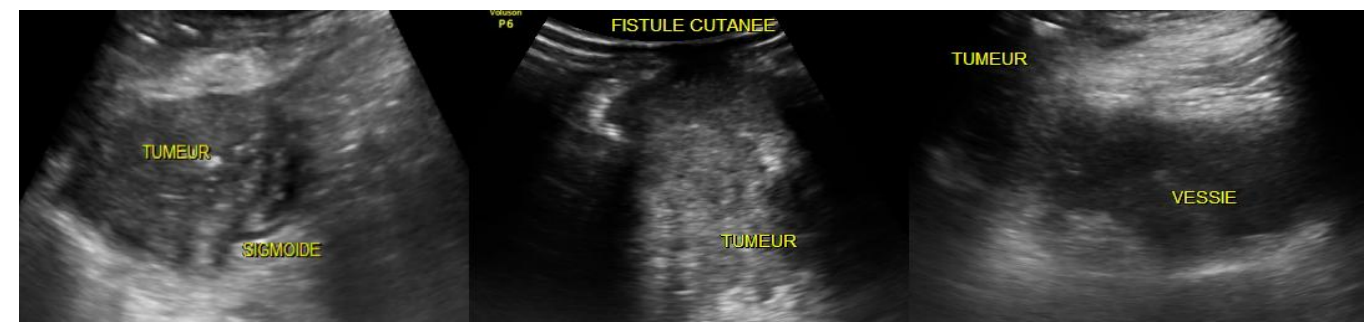

Fig-1: Ultrasound axial sections demonstrating the tumor arising from the bladder, with cutaneous fistula and close contact with the sigmoid 


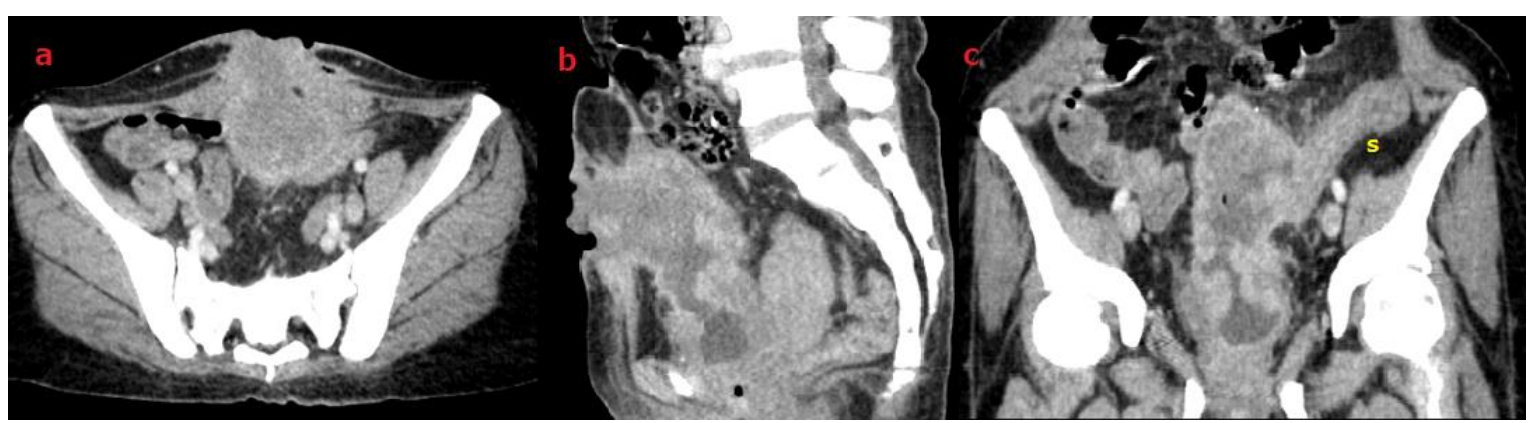

Fig-2: axial (a), sagital (b) and coronal (c) CT sections on portal veinous injection demonstrating an heterogenous tumor between the umbilicus and the bladder, with cutaneous fistula, surrounding fat stranding and infiltration of the sigmoid(s)

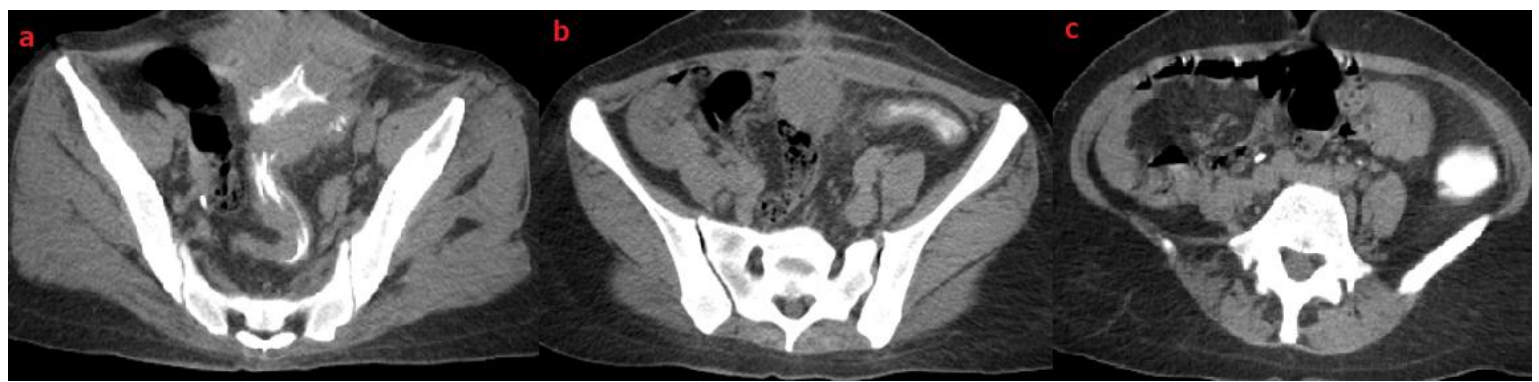

Fig-3: axial CT sections on delayed injection phase showing an opacification of the sigmoid extending to the descending colon indicating an urachal-sigmoid fistula

\section{DISCUSSION}

Urachal cancer is a rare form of bladder cancer that arises from the urachus, a vestigial musculofibrous band that extends from the dome of the bladder to the umbilicus [1].

Urachal cancers are rare and aggressive cancers of the bladder which were originally described by Hue and Jacquin in 1863. They account for only $0.5 \%$ of all bladder cancers, and $20 \%$ to $40 \%$ of primary bladder adenocarcinomas [2].

Few cases are reported in literature making it difficult to determine how best to treat these cancers. Because early urachal cancer is not accompanied with symptoms, patients often present at the time of diagnosis with higher stage and poor prognosis, the most common symptom is hematuria [3]. In our case, it was the suprapubic mass with cutaneous fistula with purulent secretions that revealed the tumor.

Imaging plays also an invaluable role at urachal cancer workup. On Ultrasound (US), it is commonly recognized as a midline soft tissue mass or a fluid-filled cavity with mixed echogenicity and calcifications. CT scan is often used for local staging and evaluation of distant metastasis. It is usually depicted as a midline mass, superior to the bladder dome and adjacent to the abdominal wall. In the majority of cases, the tumor is mixed solid and cystic, the latter representing its mucin composition. Peripheral calcifications are often seen and are considered pathognomonic for urachal adenocarcinoma $[4,5]$.
Urachal-sigmoid fistula is extremely rare, reported in only few cases [6] to our knowledge, this is the first reported case of an urachal-sigmoid fistula secondary to an urachal adenocarcinoma.

The gold standard surgical approach for the management of localized urachal cancer is an excision of the urachus, umbilicus, and cystectomy combined with bilateral pelvic lymphadenectomy [7].

\section{CONCLUSION}

Urachal carcinoma is rare disease, sigmoid fistula is even less common as we believe it is to our knowledge the first reported case of an urachal-fistula associated with an urachal adenocarcinoma. The diagnosis is based on imaging especially on CT scan showing the tumor and its extension.proper surgical intervention has proven critical to the survival of patients

\section{REFERENCES}

1. Christine Elser, Joan Sweet, A Case of metastatic urachal adenocarcinoma treated with severe different chemotherapeutic regimens, Can Urol Assoc J. 2012 Feb; E27-E31

2. Wright JL, Porter MP, Li CI. Differences in survival among patients with urachal and nonurachal adenocarcinomas of the bladder. Cancer. 2006; 4:721-8.

3. Molina JR, Quevedo JF, Furth AF, Richardson RL, Zincke H, Burch PA. Predictors of survival from urachal cancer: a Mayo Clinic study of 49 cases. Cancer. 2007; 110(11):2434-2440. 
4. Tufan Çiçek, Umut Gönülalan, Gökçen Çoban, Hilal Erinanç, Murat Koșan, "A Rare Cause of Urachal Adenocarcinoma: Urachal Diverticle", Case Reports in Urology; 2013.

5. Willian Schmitt, Marta Baptista, Marco Ferreira, António Gomes, Ana Germano, "Urachal Adenocarcinoma: A Case Report with Key Imaging Findings and Radiologic-Pathologic Correlation", Case Reports in Radiology. 2018, Article
ID 4935261, 5 pages, 2018. https://doi.org/10.1155 /2018/4935261

6. Daniel, Rapoport, Urachal-sigmoid fistula associated with diverticular disease, Can Urol Assoc J. 2007 Mar; 1(1): 52-54.

7. Herr HW, Bochner BH, Sharp D, Dalbagni G, Reuter VE. Urachal carcinoma: contemporary surgical outcomes. J Urol. 2007; 178(1):7478. Discussion 8 . 